\title{
Hemoglobina glicada: ações para sua utilização com base no conhecimento científico
}

Estima-se em próximo a 10 milhões o número de portadores de diabetes melito (DM), inclusos tipo 1 e tipo 2, no Brasil da atualidade.

Dados de prospecção sobre a forma de tratamento desses pacientes permitem afirmar que apenas uma pequena parcela tem acesso a tratamento especializado e/ou dispõe de adequado aparato de acompanhamento clínico (instalações, exames complementares, medicamentos, insulina, suporte dietético, etc.). Embora seja doença amparada pelo Sistema Único de Saúde, que garante oferta de atenção médica universal e de forma não-contributiva, o paciente diabético brasileiro ainda não usufrui significativamente do melhor conhecimento disponível sobre essa doença.

Complicações relacionadas ao estado hiperglicêmico, como falência renal e retinopatia e neuropatia diabéticas, são apontadas como responsáveis pela necessidade de oferta de elevado número de leitos hospitalares e cuidados médicos de altíssimo custo.

São tintas sombrias e de poucas luzes, mas que, no momento em que este editorial é escrito, podem estar começando a ser associadas a tons mais suaves e menos obscuros. Juntas, a Sociedade Brasileira de Endocrinologia e Metabologia, a Sociedade Brasileira de Patologia Clínica/Medicina Laboratorial, a Sociedade Brasileira de Diabetes, a Associação Latino-Americana de Diabetes e a Federação Nacional das Associações de Diabéticos, cientes de sua responsabilidade e sua missão de divulgação do conhecimento, dispuseram-se, sob múltipla e profícua regência, a elaborar um documento de consenso sobre o tema Importância da Hemoglobina Glicada $\left(\mathrm{HbA}_{1 \mathrm{c}}\right)$ para Avaliação do Controle Glicêmico em Pacientes Diabéticos: Aspectos Clínicos e Laboratoriais.

Ao ser publicado este número do Jornal Brasileiro de Patologia e Medicina Laboratorial, tal documento já deverá estar acessível à comunidade médica brasileira e aos principais interessados, os nossos pacientes, apoiado pelo melhor conhecimento científico a respeito da doença e de seus marcadores de controle terapêutico. A tarefa, bem-sucedida, impõe novas responsabilidades: por meio de implantação eficaz e necessária revisão periódica de orientações escritas, atingir uma elevada efetividade do controle terapêutico do DM, diminuindo, conseqüentemente, o número de portadores de suas complicações.

Mãos à obra! 